\title{
Influence of the condition of the surface layer of a hob cutter sharpened using the MQL-CCA hybrid method of coolant provision on its operational wear
}

\author{
Wojciech Stachurski ${ }^{1} \cdot$ Krzysztof Nadolny $^{2}$
}

Received: 27 January 2018 / Accepted: 26 June 2018 / Published online: 3 July 2018

(C) The Author(s) 2018

\begin{abstract}
This article presents the results of research on the influence of the condition of surface layers obtained after grinding a hob cutter tool face using the hybrid combined minimum quantity lubrication (MQL) and compressed cold air (CCA) (MQL-CCA) method of delivering the coolant, on its wear. In the MQL-CCA method, the minimum quantity of the lubricating (MQL) and the cooling agents, in the form of cooled compressed (CCA), were introduced into the grinding zone, simultaneously. For comparison, the tests were also conducted by separately applying the coolant with the WET method with MQL, as well as CCA. In the scope of the described grinding conditions, applying the MQL-CCA method does not cause considerable microhardness of the surface layer as compared to "wet" machining (WET). In addition, the surface roughness obtained through the application of the MQLCCA method and expressed with 2D and 3D parameters is comparable to that obtained in grinding with the WET method. SEM images for the MQL-CCA and WET methods did not reveal any typical defects in the form of burrs or chippings, occurring on the edges of the ground surfaces. The wear curves corresponding to hobs ground with the application of the coolant using the WET method and using the MQL-CCA method show similar courses, which is indicative of a lack of influence of the surface layer condition resulting from providing coolant during grinding onto intensity of the tool wear process in tangential hobbing. This conclusion is also confirmed by the similar number of teeth affected by measurable wear signs. Therefore, using the hybrid MQLCCA method, which decreases the amount of coolant provided during the grinding of hob cutters, may constitute, in the described scope of the grinding conditions, an alternative to grinding processes carried out most often with the WET method which entails considerable expenditures for purchasing, maintaining, and utilization of the coolant.
\end{abstract}

Keywords Hob cutters $\cdot$ Grinding $\cdot$ Minimum quantity lubrication $\cdot$ Cold air gun $\cdot$ Gear milling $\cdot$ Wear

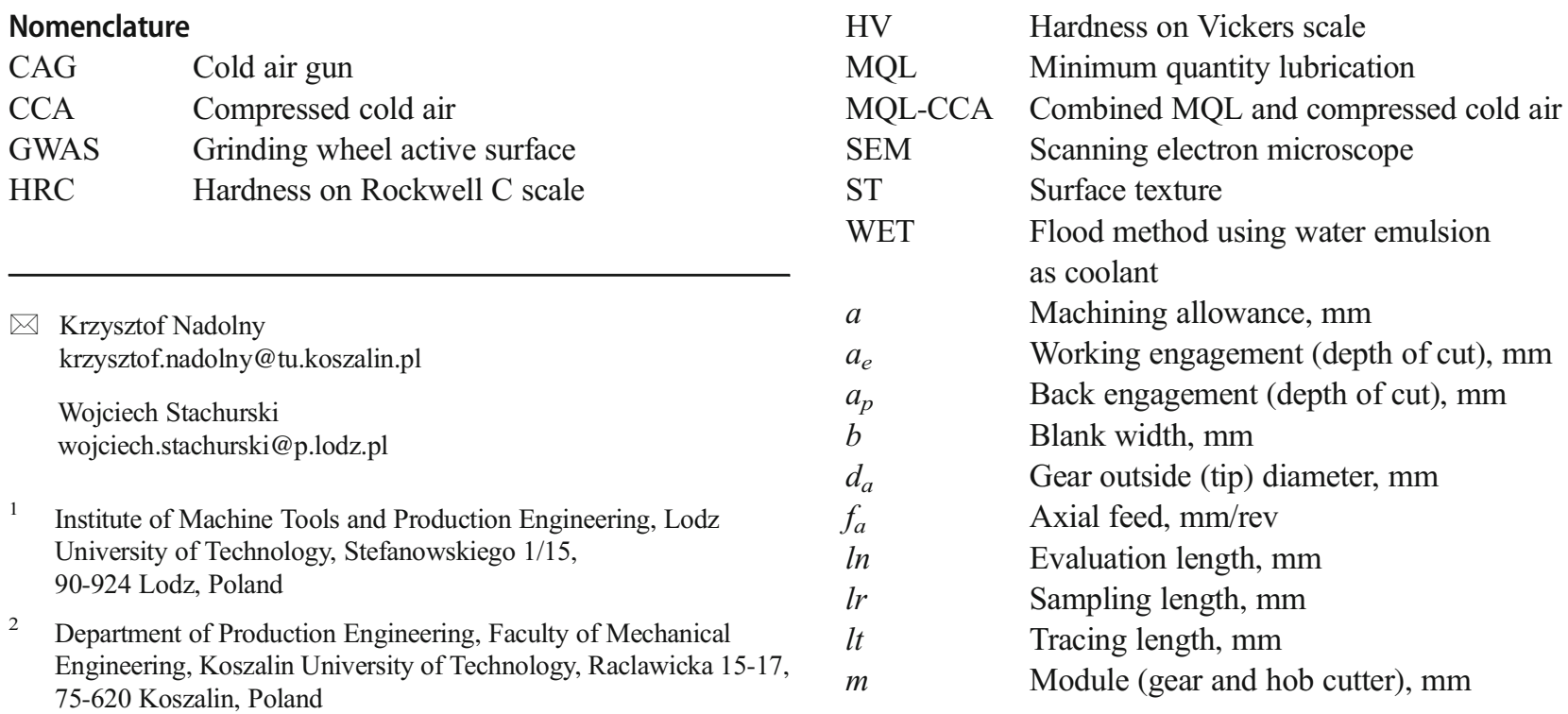




$\begin{array}{ll}n & \text { Hob cutter rotational speed, rpm } \\ n_{p} & \text { Gear rotational speed, rpm } \\ n_{s} & \text { Grinding wheel rotational speed, rpm } \\ p & \text { Air pressure (for CCA jet grinding), MPa } \\ Q_{d} & \text { Diamond dresser mass, kt } \\ Q_{\mathrm{WET}} & \text { Coolant flow rate in flood method, } 1 / \mathrm{min} \\ Q_{\mathrm{HOB}} & \text { Oil flow rate, } 1 / \mathrm{min} \\ Q_{\mathrm{MQL}} & \text { MQL fluid flow rate, } \mathrm{ml} / \mathrm{h} \\ R z & \text { Maximum height of the roughness profile } \\ & \text { within a sampling length, } \mu \mathrm{m} \\ S k & \text { Core roughness depth, } \mu \mathrm{m} \\ S p k & \text { Reduced summit height, } \mu \mathrm{m} \\ S s k & \text { Skewness of the topography height } \\ & \text { distribution } \\ S z & \text { Ten-point height of the surface, } \mu \mathrm{m} \\ r_{\text {tip }} & \text { Stylus tip radius, } \mu \mathrm{m} \\ t & \text { Machining time, min } \\ T & \text { CCA temperature, }{ }^{\circ} \mathrm{C} \\ v_{c} & \text { Cutting speed, } \mathrm{m} / \mathrm{min} \\ v_{s} & \text { Grinding wheel peripheral speed, } \mathrm{m} / \mathrm{s} \\ v_{t} & \text { Tracing speed, mm/s } \\ v_{w} & \text { Workpiece peripheral speed, m/min } \\ \mathrm{VB} & \text { Flank wear land in the corner areas } \\ & \text { of the tooth, mm } \\ x & \text { Coefficient of profile shift } \\ z & \text { Number of teeth (gear) } \\ z_{h} & \text { Number of cutting blades (hob cutter) } \\ \alpha & \text { Pressure angle (gear and hob cutter), } \\ \beta & \text { Helix angle, }{ }^{\circ} \\ \lambda c & \text { Long-wave profile filter (cutoff), } \mathrm{mm} \\ & \end{array}$

\section{Introduction}

The wear of cutting tool blades in the usage process entails the necessity of their periodic regeneration. What is used in the case of uniform tools is the process of regeneration through grinding which essentially consists in grinding the tool face and/or the cutting blades flank face. The main goal of grinding performed in such a way was to restore the blunted blades' cutting properties which depend mainly on the proper geometric shape, as well as the physical and mechanical properties of the surface layer. One of the processing methods in which the properly performed tool grinding process exerts significant influence on the precision and quality of the parts created with it is the tangential hobbing of cogwheels with hob cutters [11, 19]. This happens because during hobbing, subsequent cutting blades are exposed to uneven loads with the cutting forces that are variable in time $[8,32]$. Considerable mechanical and heat loads occur in the area of contact between the chip and the workpiece with the tool blades $[14,24]$. Taking this into consideration, the process of regenerating hob cutters should restore their original geometry and properties of the ground blades' surface layer with the greatest possible precision.

The basic materials used for grinding hob cutters are sintered carbides and fast finishing steel. It should be noted, however, that despite the increasing demand for cutting tools made from sintered carbides, tools from fast finishing steel are still commonly used as their cheaper alternative. During the grinding of fast finishing steels, as a result of friction between the abrasive grains and the ground surface and of plastic deformations in the machined material, substantial amounts of heat are produced. This causes major thermal stresses that lead to the occurrence of a network of cracks in the surface layer of the tools being ground $[15,19]$, while the high temperature in the tools' surface layer can cause structural changes that considerably decrease the blade's cutting properties [18]. In improper grinding conditions of fast finishing steel, the surface layer may be composed of a re-hardened layer and a tempered zone located underneath it or just a single re-hardened layer of minor thickness.

The most effective way of decreasing the temperature during grinding is by applying a coolant. Of the numerous methods of its delivery into the grinding zone, the most popular is the WET method (WET) $[9,17]$. From the technical perspective, the basic inconvenience of this delivery method is the high coolant flow rate and the fact that only a minor part reaches the area of contact between the grinding wheel and the material being machined [23]. It is also estimated that the costs of coolant application (purchasing, cleaning, regeneration, and utilization) constitute up to $17 \%$ of the total production costs and are considerably higher than the tool costs $(2-4 \%)$ [10]. The goal is, therefore, to completely eliminate or reduce the coolant flow rate for economic reasons. Moreover, environmental reasons also lie behind this approach, along with the necessity to meet the increasingly more demanding requirements in the field of environmental protection and employee safety [27].

The above-mentioned drawbacks related to the conventional WET method may be limited by using alternative lubricating and cooling methods [3]. One of the most frequently used alternative methods is the minimum quantity lubrication method called MQL [30]. The MQL method consists of the constant production of an oil mist and applying it directly into the grinding zone, usually onto the grinding wheel active surface (GWAS). The flow of the fluid is facilitated by the usage of a transporting agent - a stream of compressed air which also performs the role of a minor cooling agent [3, 18]. Literature review showed that the oil-aerosol in the grinding process is delivered to the machining zone usually with a volume of $20-100 \mathrm{ml} / \mathrm{h}[2,28,30,31,37]$. The results of research work conducted in various scientific centers point to the effectiveness of the MQL method in a variety of grinding process types. This concerns, for example, the flat surface grinding process $[2,28]$ or the internal cylindrical grinding of internal surfaces [31]. The authors of the above-cited works have proved that in specific machining conditions, the 
application of the MQL method brings about results comparable, or even better than those obtained in the WET method. What was observed, among other things, was a decrease in the machined surface roughness, a decrease in the grinding force, thus extending the grinding wheel life and limiting its volumetric wear. Despite the MQL method's advantages related to its good lubricating properties, its apparent disadvantage is a lack of sufficient cooling properties in a wide range of changes of grinding process parameters as compared with the traditional WET method [5]. This results mainly from the relatively low heat storage capacity of the oil and air and from the small amount of the coolant delivered into the grinding zone. For this reason, in recent years, work has been conducted on improving the cooling effectiveness in the MQL method by combining it with cryogenic cooling or with applying a stream of cooled compressed air (CCA) [22, 27]. What is worth noting is the fact that using air as a cooling medium does not increase costs connected with the obtaining and utilization of environmentally harmful coolants as it is only necessary to purchase coolant to be applied in the MQL method. Another advantage of combining the MQL and CCA methods is the low cost of purchasing devices delivering the cooling and lubricating agents into the grinding zone, as well as the user-friendliness of these devices. A cooled compressed air stream can be obtained using cold air gun (CAG) nozzles [16]. CAG nozzles are powered with filtered compressed air and thanks to application of vortex tubes in their construction, the compressed air stream can be maintained at a temperature below $0{ }^{\circ} \mathrm{C}$.

The study by Nguyen et al. [20] describes the tests carried out during surface grinding with a cold air and oil mist (CAOM) system. Experiments were conducted on plain carbon steel 1045 with an aluminum oxide wheel ground at different depths of cut of 5,10,15, and $20 \mu \mathrm{m}$. During the experiment, air cooled down to $-20{ }^{\circ} \mathrm{C}$ was fed to the grinding wheel active surface through a single nozzle. At the same time, a second nozzle was used to deliver vegetable oil, with an output of $0.16 \mathrm{ml} / \mathrm{min}$, to the grinding wheel active surface using the MQL method. The results show that the already-low oil mist output, combined with the application of CCA, allows one to increase the grinding depth without the simultaneous occurrence of burns on the surface of the workpiece. At the same time, the surface cleaning ability of CAOM is worse than that of coolant, thus causing a slight increase of ground surface roughness.

Another way to deliver cooled air and oil to the machining zone at the minimum quantity is by using the chilled air minimum quantity lubrication (CAMQL) method. In this method, the oil fed at the minimum output MQL is dispersed and delivered to the machining zone by a cooled compressed air stream (chilled air) [29]. Both agents are combined in a special design nozzle. A paper by Saberi et al. [26] describes research using the CAMQL method during plunge surface grinding. During the experiment, samples made of CK45 (90 \pm 3
HRB) steel with an aluminum oxide wheel were ground. Oil expenditure in the MQL method was $120 \mathrm{ml} / \mathrm{h}$. The output cold air pressures were $0.1,0.2,0.3$, and $0.4 \mathrm{MPa}$ at $-4,1,7$, and $14{ }^{\circ} \mathrm{C}$, respectively. As a result of the research, it was found that the tangential grinding forces and friction coefficient of the CAMQL technique are lower than those of fluid cooling and dry grinding. This leads to a reduction of power consumption which is linked with environmental pollution. At the same time, the roughness of the CAMQL surface was higher than the surface shaped using the dry or flood methods.

Sanchez et al. [27] presented a concept based on the application of the method of hybrid coolant delivery with MQL with $\mathrm{CO}_{2}$ low-temperature gas during the grinding of X153 CrMoV12-1 (AISI D2) tool steel with the use of an alumina grinding wheel. In this method, known by the acronym minimum coolant grinding (MCG), both the oil mist and $\mathrm{CO}_{2}$ streams are not directed directly into the grinding zone but are sprayed onto the grinding wheel active surface. The sequence in which the individual nozzles are positioned ensures that the oil droplets that penetrate spaces between the abrasive grains and move with the rotation of the grinding wheel are rapidly cooled down before they enter the contact area of the grinding wheel with the workpiece. According to the authors, the main task of this method is to protect abrasive grains from wear, which mainly translates into a significant increase in the durability of the wheel, as well as an improvement in the quality of the machined surface. Measured microhardness values in the surface layer showed no significant differences compared with wet grinding. The temperature of the material ground with the use of the MCG method did not exceed the limit value responsible for thermal defects. In a later publication [12], the authors described research on the optimization of the MCG method in order to achieve lower oil and $\mathrm{CO}_{2}$ expenditures and thus reduce manufacturing costs in industrial production.

It is worth noting that grinding with the use of the abovedescribed methods of delivering coolant to the machining zone does not solve the issue of the removal of chips located among the abrasive grains. This leads to a clogging of free intergranular spaces in the grinding wheel active surface and a deterioration in the quality of the machined surface. Oliveira et al. [21] described tests in which compressed air jets were used to clean the active surface of the grinding wheel. The test results show that MQL grinding in combination with a stream of cleaning air ensures a better surface roughness than using the flood or MQL method without a cleaning jet in a specific range of conditions. Another example of using compressed air to clean the grinding wheel active surface during external cylindrical plunge grinding was described in a paper by Bianchi et al. [6]. In this study an AISI 4340 (60 hardness on Rockwell C scale (HRC)) steel was ground using a white fused alumina grinding wheel with a vitrified bond. The results show that the application of the MQL method assisted 
with a wheel cleaning jet (MQL + WCJ) during the machining process allows one to obtain more favorable parameters of the surface layer, such as roughness and microhardness, compared with the surface ground with the use of the MQL method without a wheel cleaning jet. The results of the tests described in other studies [7, 25] confirm the above-described positive influence of the use of the compressed air stream to clean the grinding wheel active surface on the results of the grinding process.

The current literature does not contain any comprehensive research on the application of methods eliminating or decreasing the amount of coolant applied in grinding hob cutters. This topic was discussed in a study [36] where the authors presented their own original solution of applying cooling agents that they named with the acronym MQL-CCA. This consists of the simultaneous application of the coolant using the MQL method and cooled compressed air (CCA) using a cold air gun $(\mathrm{CAG})$ into the machining zone. In their research, the authors evaluated the influence of the application of the MQL-CCA method onto the face surface layer after grinding described with such parameters as microhardness and roughness, while also assessing the condition of the cutting blades on basis of scanning electron microscope (SEM) images. The abovedescribed analyses were the result of research on the hob cutters' face surface grinding process in a single pass.

An important, but so far untouched issue is determining the influence of the surface layer condition obtained as a result of grinding the hob cutter face using the coolant applied with the MQL-CCA method onto the service wear of the tool. In a further part of this article, the authors describe experimental tests concerning this issue. Section 2 discusses the test conditions in grinding hob cutters and in the tangential hobbing of cogwheels with the previously ground cutters. Section 3 contains an analysis of the measurements of parameters describing the cutter face surface condition after grinding (microhardness, roughness) and of SEM images of the cutting blades' edges. Section 4 presents an analysis of the wear assessment by discussing the number of cutter teeth affected by measurable wear signs and the course of wear for the most affected hob cutter tooth. Chapter 5 includes conclusions drawn from the conducted research.

\section{Experimental tests}

The goal of the experimental tests was to evaluate the influence of the surface layer condition obtained in grinding hob cutters using various coolant provision methods on the course of the cutters' service wear. During the first stage of the tests, the cutters' blades were ground using the hybrid MQL-CCA method for cooling and lubricating the grinding zone. For comparison, tests were also conducted on grinding using coolant delivered with the WET and MQL methods, as well as using only CCA. The tests were conducted by removing the allowance in 10 passes, then measuring the microhardness and roughness of the machined surface and registering SEM images. In the second stage, tests on the previously ground hob cutters' service wear were conducted by periodically measuring the wear of the cutter's teeth flank face expressed with parameter VB.

\subsection{Grinding hob cutters' blades}

\subsubsection{The test station and methodology}

The flank face of monolithic hob cutters made from HS6-5-2 high-speed steel (HSS) without an anti-wear cover (Fig. 1) was ground. These hob cutters are used for producing cylindrical cogwheels that comply with ISO 53 and ISO 54 norms.

The cutters were ground on a special conventional grinder for grinding hob cutters using a 38A60KVBE plate grinding wheel, manufactured by Norton. This is a grinding wheel made from sintered fused alumina with a ceramic bond. Such grinding wheels are advised for the precise and finishing grinding of hard (> $57 \mathrm{HRC}$ ) steels sensitive to burns, e.g., fast finishing steel. The grinding wheel was dressed prior to each test, using a 1-point diamond dresser. The parameters of grinding the hob cutters' blades were selected on basis of data in the literature $[4,13]$ and workshop practice. The allowance $a=$ $0.3 \mathrm{~mm}$ was removed in 10 work cycles consisting of a grinding and return stroke, using a grinding depth of $a_{e}=0.03 \mathrm{~mm}$ for each cycle (Fig. 2). Table 1 presents a comparison of the grinding conditions applied during the described tests.

In grinding the cutters, a method, developed by one of the authors, was used that consists of the simultaneous application

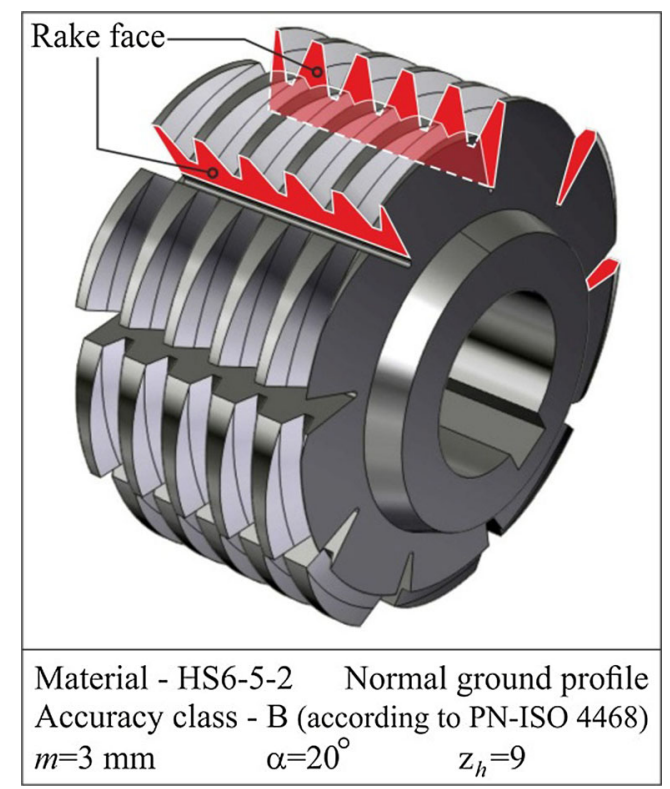

Fig. 1 Hob cutter used in the experimental investigations 
Fig. 2 Diagram of the hob cutter sharpening process: a machining allowance; b work cycle

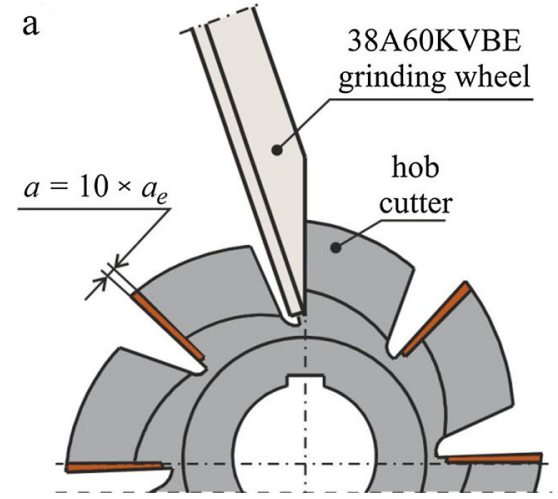

of an oil mist with a minimum quantity of the lubricant (MQL) and cooled compressed air (CCA), namely the MQL-CCA method $[33,36]$. An external device, namely a MicroJet MKS-G100 manufactured by Link GmbH (Germany), equipped with a single atomizing nozzle, was employed to produce the oil mist. As the coolant in the MQL method is oil based on synthetic esters, Biocut 3000 was used and was provided by the tool's producer. CCA was delivered into the grinding zone using a single CAG nozzle cooling the compressed air with a 6910.15.3-7 manufactured by WNT GmbH (Germany). Figure 3 presents the oil mist and the nozzle delivering the cooled compressed air in relation to the grinding wheel active surface.

Coolant in the form of an oil mist was introduced into the grinding zone using the nozzle on the right side of the hob

Table 1 Grinding conditions

\begin{tabular}{ll}
\hline Grinding mode & Hob resharpening \\
\hline Grinding machine & Conventional hob grinding machine \\
Workpiece material & HS6-5-2 high-speed steel, hardened \\
& with $62 \pm 1 \mathrm{HRC}$ \\
Grinding wheel & 38A60KVBE, dish (type 12) grinding \\
& wheel \\
Dressing parameters & Single-point diamond dresser $Q_{d}=1.0 \mathrm{kt}$ \\
Grinding parameters & $n_{s}=2950 \mathrm{rpm}, v_{w}=31 \mathrm{~m} / \mathrm{s}$, \\
& $v_{w}=6.6 \mathrm{~m} /$ min, $a=0.3 \mathrm{~mm}$, \\
& $a_{e}=0.03 \mathrm{~mm}$ \\
Environments & WET \\
& Fluid: $5 \%$ water solution \\
of Emulgol ES-12 oil \\
$Q_{\text {WET }}=51 / \mathrm{min}$ \\
MQL \\
System: MicroJet MKS-G100—oil mist \\
generator with single external nozzle \\
Fluid: Biocut 3000 \\
$Q_{\mathrm{MQL}}=50 \mathrm{ml} / \mathrm{h}$ \\
CCA \\
System: WNT 6910.15.3-7—cold air gun \\
with single nozzle \\
$p=0.6 \mathrm{MPa}$ \\
$T=-5{ }^{\circ} \mathrm{C}$ \\
MQL-CCA \\
\\
\end{tabular}

cutter, while the cooled compressed air was provided from the left side of the hob cutter through a second nozzle. The outlets of both nozzles were placed at a distance of $15 \mathrm{~mm}$ from the grinding wheel active surface. The grinding wheel, turning clockwise, lifts the oil mist and moves it into the grinding zone, while the CCA stream cools the grinding zone and minimizes the phenomenon of the grinding wheel gumming up by removing chips and grinding products left after exiting the grinding zone from its active surface.

For comparative purposes, grinding using oil emulsion delivery with the WET method was also conducted, namely the application of oil mist with MQL and the delivery of CCA - Fig. 4.

Water oil emulsion, using Emulgol ES-12 oil (5\%), was employed as the conventional machining fluid. The coolant in the MQL method was applied through a single-atomizing nozzle set just as in the MQL-CCA method. The cooled compressed air was delivered into the cutting zone also through a single nozzle. The nozzle was located on the right side of the grinding wheel while its outlet directed the air stream into the area of contact between the grinding wheel and the workpiece.

\subsubsection{Measurements of microhardness, roughness, and SEM observations of the hob cutters' surface after grinding}

Measurement of hob cutters' face surface microhardness after grinding were made using the KB10BVZ-FA microhardness testing machine manufactured by KB Prüftechnik

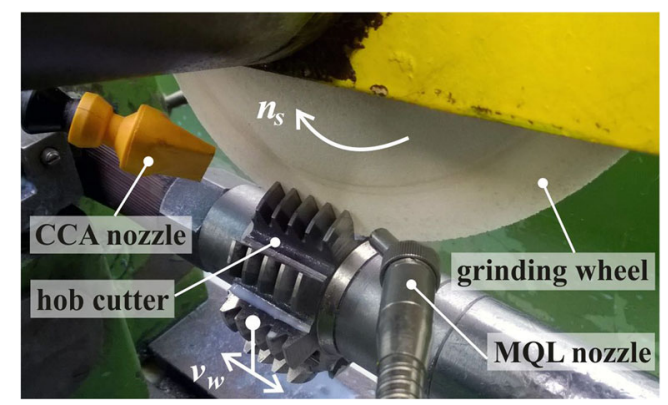

Fig. 3 Arrangement of the oil mist nozzle (MQL) and the supply nozzle of cooled compressed air (CCA) relative to the grinding wheel active surface in the MQL-CCA method 
Fig. 4 Arrangement of the coolant supply nozzle: a WET; $\mathbf{b}$ MQL; c CCA
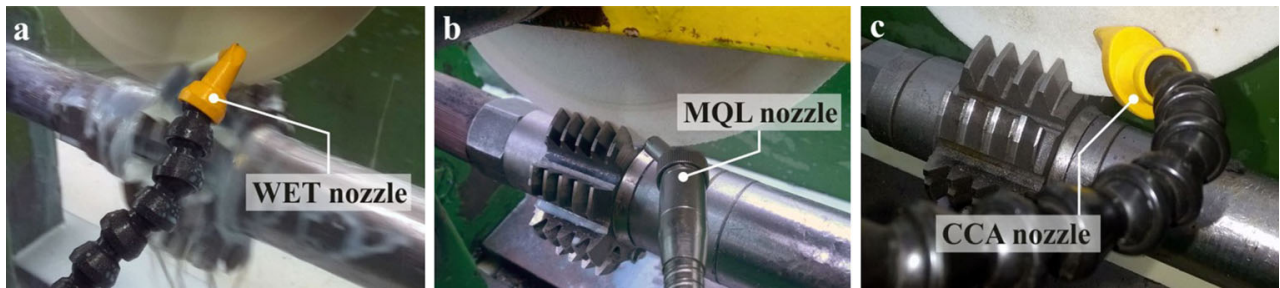

GmbH (Germany). Microhardness was determined on the Vickers' scale with a force of $0.9807 \mathrm{~N}$, in compliance with PN-EN ISO 6507. The measurements were conducted on joints perpendicular to the face surface up to a depth of $100 \mu \mathrm{m}$ from the ground surface. For each joint, three microhardness measurements were conducted. The obtained measurement results were then subject to interpolation using a cubic B-spline. The initial hardness of the tool material was on average 890HV0.1 ( $67 \mathrm{HRC})$.

Measurements of cutters' face surface roughness after grinding were made with a T8000 Hommel Tester profilometer, manufactured by the Hommelwerke company (Germany). The measurement conditions were determined on the basis of PN-EN ISO 3274:2011E and PN-EN ISO 4288:2011E. Moreover, 2D parameters, determined from the roughness profile and 3D parameters, obtained as a result of the surface topography, were used to describe ground surface roughness. The diagram of these parameters' measurements is presented in Fig. 5. The value of the maximum roughness profile height $R z$ (according to PN-EN ISO 4287:1999) was used as the $2 \mathrm{D}$ parameter. For each cutter, one measurement on five selected blades was made, moving the TKU 300

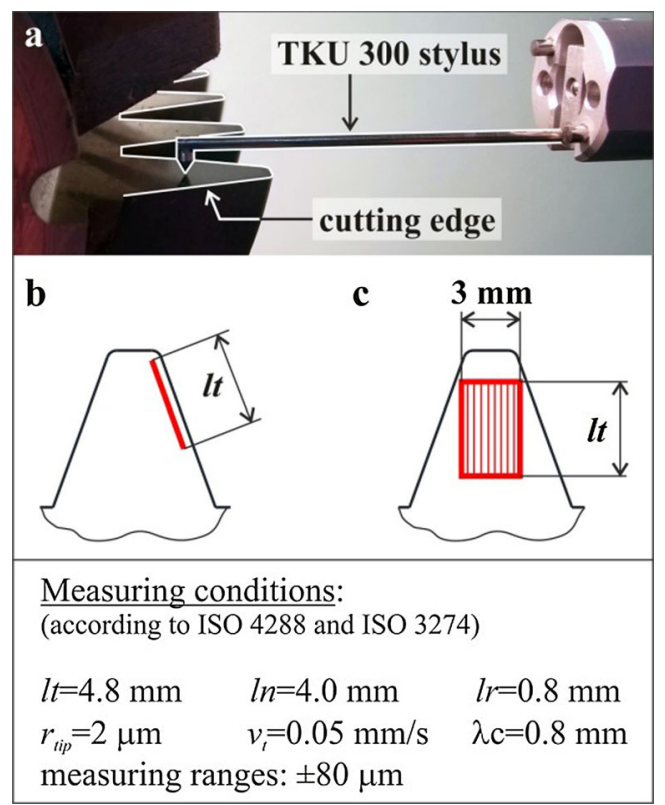

Fig. 5 Scheme of face surface roughness measurement: a general view; $\mathbf{b}$ scheme of roughness profile measurement; c scheme of surface topography measurement measurement stylus parallel to the cutting edge. The cutter face surface roughness near the cutting edge was determined by the arithmetic mean of these five measurements. Amplitude parameters $(S z, S s k)$, and the capacity curve - $(S k$ and $S p k$ ) were used as 3D parameters.

An S-3000N scanning electronic microscope (SEM) manufactured by Hitachi (Japan) was used for optical evaluation of the quality of the cutting blades. Images of cutting edges magnified 150 times were registered for each cutter. Images with $\times 500$ magnification were used for detailed analysis of sections of selected cutting edges.

\subsection{Tangential milling of cogwheels}

\subsubsection{The test station and methodology}

Cylindrical wheels with straight teeth made from steel C45 with microhardness $20 \pm 1$ HRC were envelope hobbed during the operating research (Fig. 6). The machining was conducted on an SRF1 hobbing machine manufactured by Staehely (Germany). The coolant, in the form of Ferokol EP processing oil, was delivered into the cutting zone with the WET method through a single nozzle with a flow rate $10 \mathrm{l} /$ min. The machining conditions are presented in Table 2.

The tests were begun by making cogwheels using a hob cutter ground with the application of cooled compressed air (CCA). This choice resulted from the fact that it was this cutter for which the greatest $R z$ roughness parameter was measured while considerable limitation of microhardness in relation to the cutter before the grinding was observed. Due to the fact that the hob cutters blades' teeth mainly take the form of abrasion on the flank face $[34,35]$, the hobbing was conducted until the criterion $\mathrm{VB}_{C}=0.6 \mathrm{~mm}$ was achieved (Fig. 7).

$\mathrm{VB}_{C}$ parameter determines the value of cutting edge abrasion on the flank face in the corner area within which increasing abrasion values are observed as the machining time progresses [24]. In the case of backwards cutting, this regularity concerns the corner on the side entering the machining-rolling gearing. The time necessary to achieve the assumed wear criterion value increased to $312 \mathrm{~min}$. For the three remaining hob cutters, representing the other methods of delivering the coolant during grinding (WET, MQL, MQL-CCA), the same processing time value was adopted as a criterion. 
Fig. 6 Envelope hobbing: a view of the machining zone; $\mathbf{b}$ gear wheel after hobbing
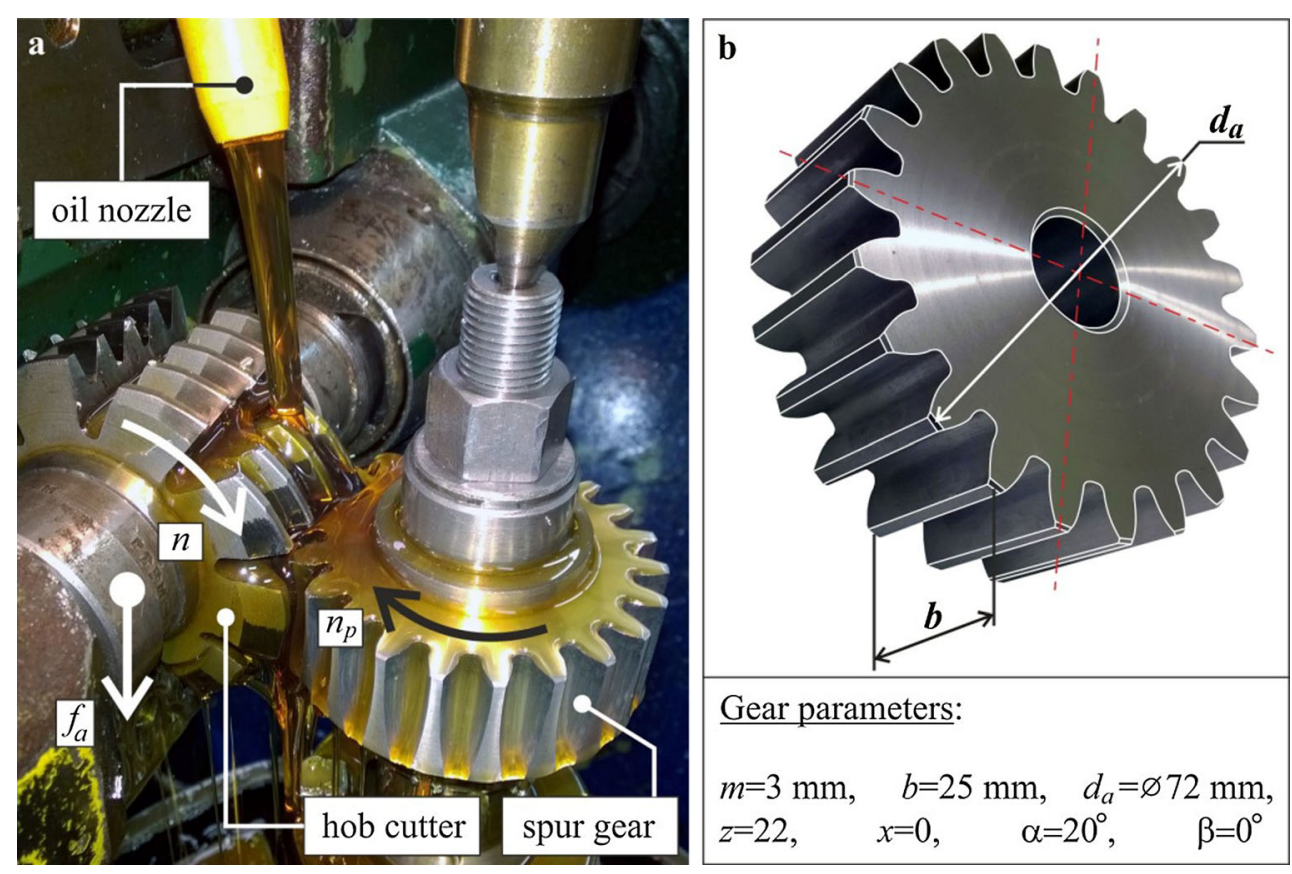

\subsubsection{Measurements of the hob cutters' wear}

Measurements of the hob cutters' wear were made on an MWDc measurement station optic workshop microscope manufactured by PZO (Poland) with a reading resolution $0.001 \mathrm{~mm}$. Blade wear, with a cutting speed of $v_{c}=32.7 \mathrm{~m} /$ min applied in the tests, occurred on the flank surfaces and took the form of abrasion near the cutting edge. No wear was observed on the rake face. The greatest value of wear described with parameter $\mathrm{VB}_{C}$ occurred near the corner on the side entering the machining-rolling gearing (Fig. 8). This value was taken into consideration when analyzing the research results.

Measurements of the cutter blades were begun from tooth number 1 . It was assumed that this tooth would be the first to have the full outline of the cutting edge (Fig. 9). The subsequent teeth were measured along the helical curve of the hob.

Table 2 Machining conditions during envelope hobbing

\begin{tabular}{ll}
\hline Process & Hobbing a spur gear \\
\hline Machine tool & Gear hobbing machine SRF1 by Staehely, \\
& Germany \\
Cutting parameters & $v_{c}=32.7 \mathrm{~m} / \mathrm{min}, f_{a}=0.567 \mathrm{~mm} / \mathrm{rev}$, \\
& $a_{p}=6.6 \mathrm{~mm}(1$ pass $), n=130 \mathrm{rpm}$, \\
& $n_{p}=5.9 \mathrm{rpm}$, up milling, without shifting \\
Cutting fluid & Ferokol EP oil given by flood method, \\
& $Q_{H O B}=101 /$ min \\
Workpiece & Spur gear with straight teeth made of C45 \\
& carbon steel, hardened with $20 \pm 1 \mathrm{HRC}$ \\
\hline
\end{tabular}

\section{Results of the tests on the hob cutters' face surface after grinding}

\subsection{Results of microhardness measurements}

On basis of structural microscopic tests of the tool material conducted prior to grinding, it was concluded that the cutter blade material displays a structure composed of tempered martensite and strips of primary carbides with a high intensity level (Fig. 10).

Figure 11 presents the microhardness profile in the cutter surface layer prior to and after grinding the face surface using the WET, MQL, CCA, and MQL-CCA methods.

Microhardness tests conducted after grinding showed that its smallest changes (approximately 25 hardness on Vickers scale (HV) at the surface), as compared to microhardness of the material before grinding, are obtained when grinding cutters use coolant in the WET mode. Microhardness changes were observed up to approximately 20-30 $\mu \mathrm{m}$ from the cutter surface.

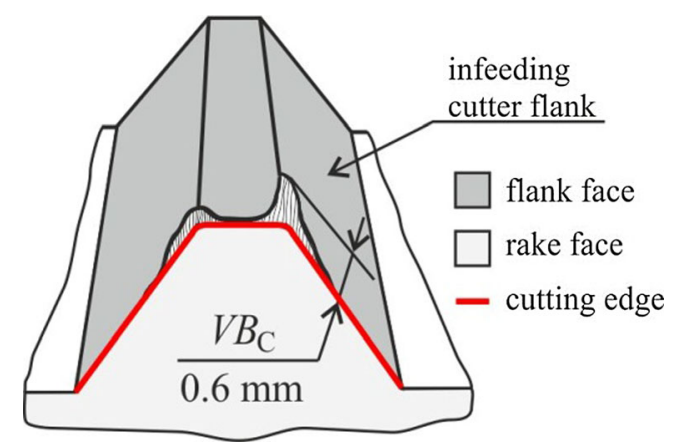

Fig. 7 Flank wear distribution on the hob cutter tooth 


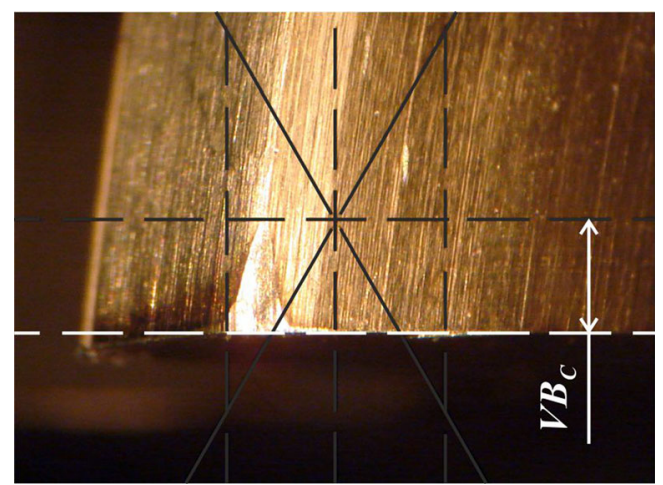

Fig. 8 Actual hob flank wear land

In the case of the simultaneous application of an oil mist and cooled compressed air with the MQL-CCA method, the changes in microhardness in relation to the material before grinding are similar to those obtained in grinding with WET cooling. The differences between the HV values obtained closest to the flank surface are 4-6 units. At the same time, changes in microhardness were observed up to approximately $40 \mu \mathrm{m}$ from the cutter grinding surface.

What is worth noting is the fact that application of the CCA method caused the limitation of microhardness to approximately $70 \mu \mathrm{m}$ from the grinding surface while microhardness at a depth of $10 \mu \mathrm{m}$ was lower by approximately $90 \mathrm{HV}$ in relation to the initial material.

Comparing the microhardness values obtained using the CCA and MQL methods a minor difference of approximately $15-25 \mathrm{HV}$ is clearly visible between them. In the case of the cutter ground with application of the coolant with minimum quantity lubrication (MQL), microhardness measured at a depth of $10 \mu \mathrm{m}$ was smaller by $12 \mathrm{HV}$ units as compared to the cutter ground with cooling using the CCA method.

It should be remembered that changes in microhardness of the surface layer obtained after grinding are mainly the result of changes in the machined material structure taking place

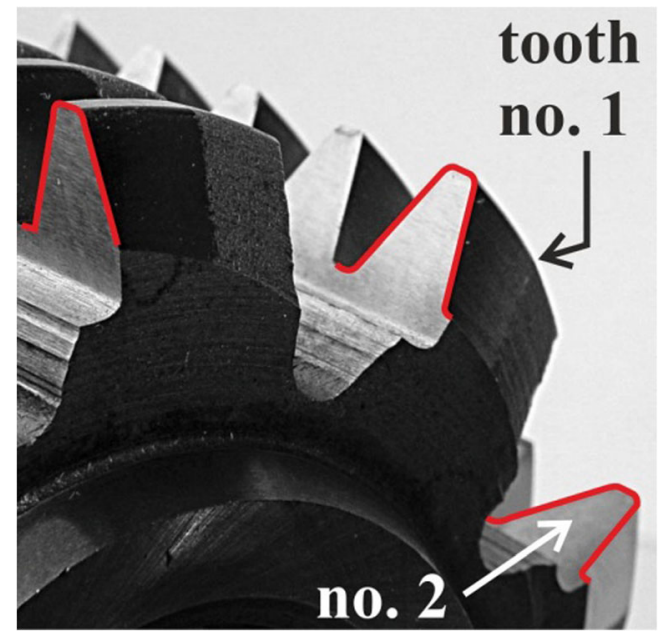

Fig. 9 Selection of tooth no. 1

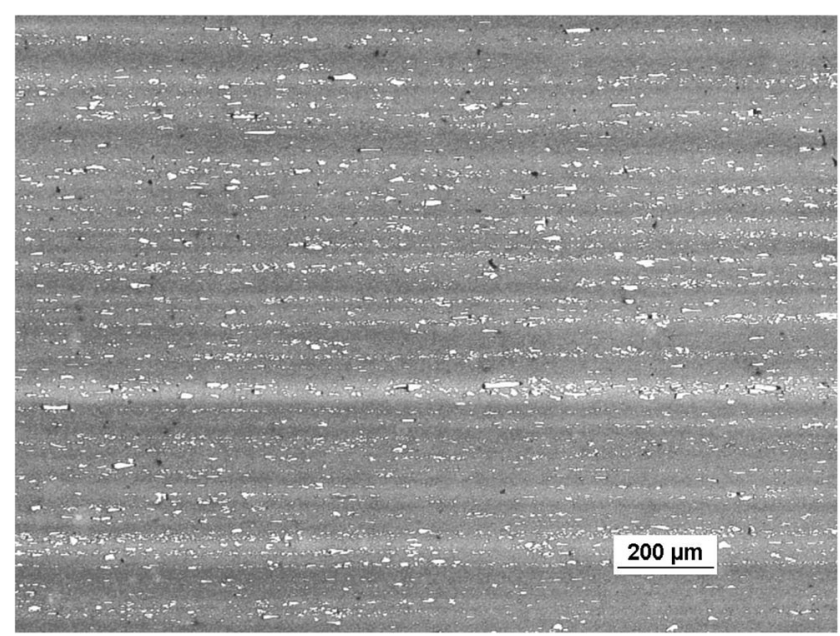

Fig. 10 Surface metallography of the hob cutter (mag. $\times 500$, etched using $\mathrm{Mi1Fe}$ )

under the influence of heat whose source is the plastic deformations occurring during chip creation and friction. The heat penetrating the workpiece is the cause of temperature increase in the surface layer that leads to the tempering of a thin surface layer and decreasing its microhardness. An advantageous decrease in the temperature value in the surface layer is obtained through proper selection of input parameters of the grinding process such as: adjustment parameters (traverse, velocity); parameters characterizing the grinding wheel (abrasive material, bond, grinding wheel topography); and coolant parameters (fluid type, flow rate).

Taking the above into consideration and bearing in mind the fact that in the above-described research various methods of coolant delivery were used as the variable parameter, it may be concluded that similar microhardness values obtained during grinding with GR provided with the WET method and using the MQL-CCA method are indicative of the proper removal of heat from the grinding zone and of temperature decrease in the workpiece. At the same time, a clear decrease in the surface layer microhardness with minimum quantity of the coolant (MQL) or with the application of cooled compressed air into the grinding zone should be explained by occurrence of temperatures higher than in other cases in the workpiece - in the case of the MQL method as a result of insufficient cooling, while in the case of the CCA method, due to greater friction caused by a lack of lubrication.

\subsection{Results of roughness measurements}

Figure 12 presents the results of measurements of hob cutters' face surface roughness after grinding with various coolant provision methods. On basis of the obtained results, it was concluded that the lowest $R z$ parameter values (Fig. 12a) were measured on the face surface grinding with the delivery of Emulgol ES-12 emulsion with the WET method. In the case 
Fig. 11 Profile of microhardness in the surface layer of HS 6-5-2 steel cutter sharpened with the use of WET, MQL, CCA, and MQLCCA methods

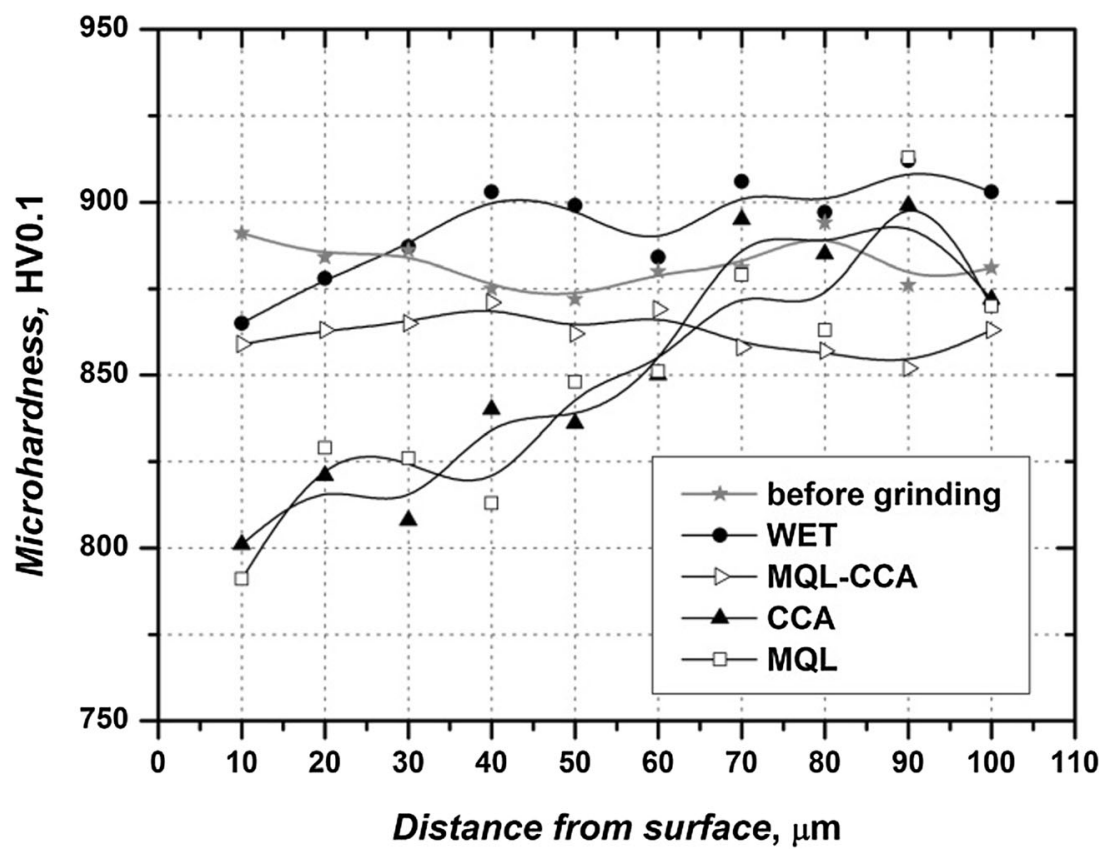

of the application of the MQL method, the obtained surface roughness was $40 \%$ higher in comparison with WET, while for the CCA method the roughness was $134 \%$ greater than in the case of WET. In the case of the simultaneous provision of an oil mist and cooled compressed air with the MQL-CCA method, it was observed that the mean roughness value expressed with parameter $R z$ is slightly higher than the analogous one obtained during the delivery of coolant with the WET method, the difference being $4.7 \%$. Obtaining for the MQL-CCA method results comparable to those obtained when applying coolant in the WET mode is particularly important, taking into consideration the fact that the roughness obtained as a result of the face surface grinding is decisive for the cutting blade quality. The higher its value, the higher the nicking of the cutting edge and, as a result, the tool wear will be more intense. This is due to abrasion of the nicks in the initial tool work period caused by the blade material's friction against the workpiece during grinding.

In analyzing the obtained $R z$ parameter values (Fig. 12a), it should be noted that the greatest value was obtained for the surface ground with the CCA cooling method, for which a considerable decrease in microhardness was also obtained (Fig. 11). As observed previously, the decrease in microhardness is caused by increase of temperature in the workpiece surface layer resulting in surface tempering. What happens in a softer material is an increase in plastic deformations during jamming of the blade, demonstrating itself in the creation of side material pick-up's with considerable height and the occurrence of the rifling phenomenon. This causes an increase in the ground surface roughness. Moreover, due to technical limitations in the layout of CCA nozzles (collision during grinding with a moving hob cutter), the cooled compressed air stream does not make it possible for the chips and other grinding products to be removed properly from the machining zone. Chips get stuck to the tempered surface and cause surface scuffing that increases the roughness on the cutter flank surface.

The $R z$ parameter value measured on the ground surface using coolant provision with the MQL method is $40 \%$ lower than the $R z$ parameter value obtained for the CCA method. This is indicative of the significant influence of the delivery of lubrication in the area of contact between the abrasive grains' active apexes and the workpiece on the ground surface roughness. This relationship is confirmed also by descriptions of research on the application of the MQL method in other variations of the grinding process $[2,31]$. As a result of distributing the coolant on the grinding wheel active surface and its penetration into the free spaces between the abrasive grains, friction between the chips created during grinding and the machined surface is also limited, while the grinding products are removed more easily from the grinding zone. It should be remembered, however, that the effectiveness of lubrication is, to a large extent, determined by, among other things, the distance of the MQL nozzle from the workpiece [37]. In the case of the above-described research, obtaining $R z$ parameters with a value of $34 \%$ higher than the value measured for the WET method indicates insufficient lubrication of the grinding zone that can be explained by too great a distance between the MQL nozzle and the grinding zone. As a result of the applied nozzle layout, part of the air-oil spray could have been dispersed by going beyond of the area of contact between the grinding wheel and the machined material, thus decreasing lubrication effectiveness, causing an increase of friction in the grinding zone and deteriorating chip removal efficiency. 

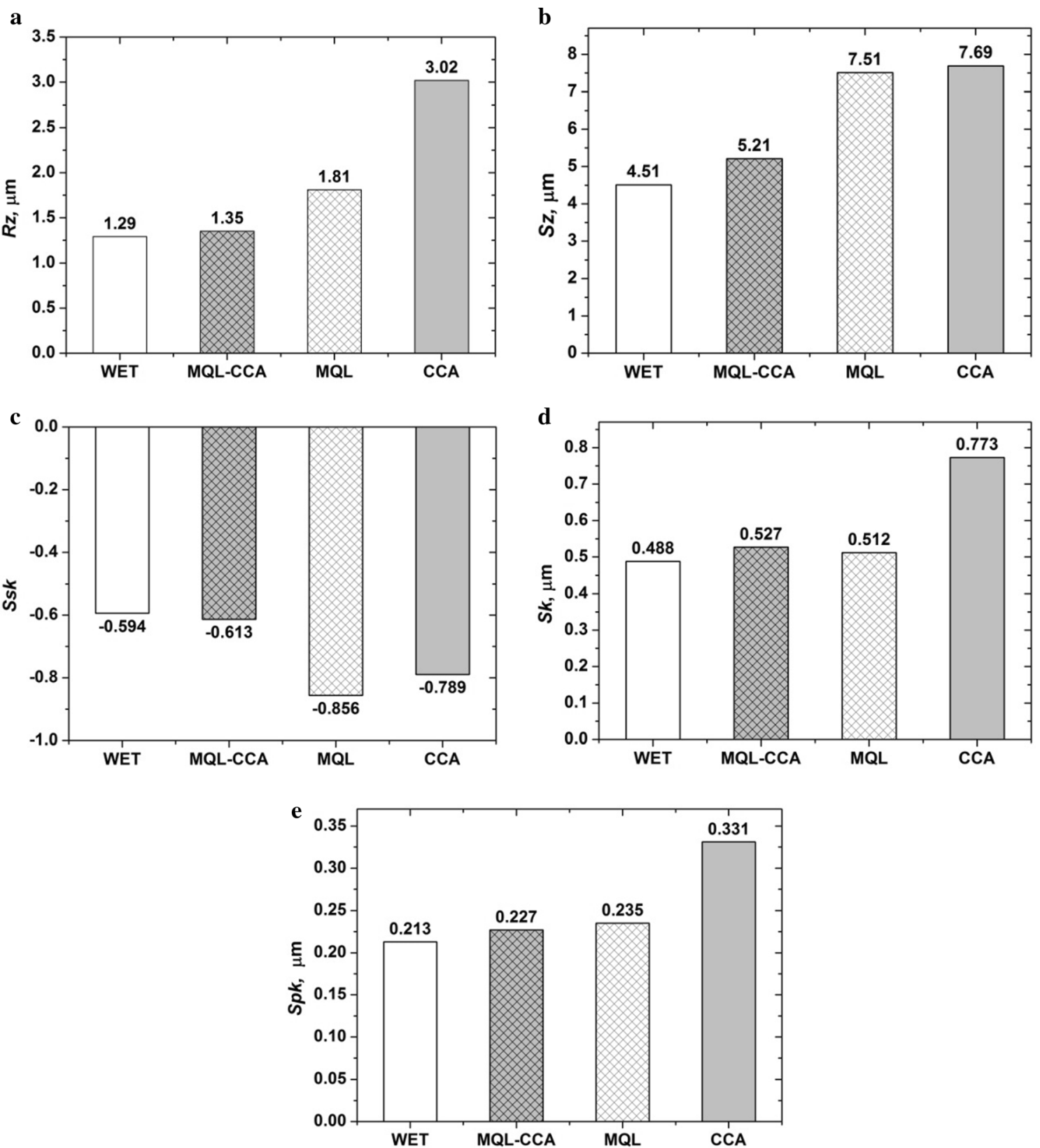

Fig. 12 Surface roughness parameters of rake face hob sharpened with different methods of coolant delivery: a $R z$, b $S z$, c $S s k$, d $S k$, e $S p k$

It should be noted that the MQL nozzle outlet was placed as closely as possible to the grinding zone, with further decrease of this distance was impossible only for technical reasons (collision during grinding with the moving hob cutter). Increasing friction in the grinding zone, combined with its insufficient cooling (characteristic for the MQL method) caused, due to the heat accumulated in the workpiece after subsequent passes of the grinding wheel, the temperature in the workpiece surface layer to lead to surface tempering, as indicated by the measured microhardness value (Fig. 11). As a result, just as in the case of the CCA method, the phenomenon of ridging, creation of side material pick-up's of considerable height and the scuffing of the tempered surface with grinding products not removed from the grinding zone contributed to increasing the surface roughness. An additional probable cause of increasing the surface roughness could have been the occurrence of the phenomenon of gumming up of the grinding wheel.

In the case of a surface for which the MQL-CCA method of coolant provision was applied during grinding, a decrease in the $R z$ parameter value occurred, which describes the roughness by $35 \%$ as compared to the cutter ground with the coolant delivered by the MQL method. At the same time, the $R z$ parameter is only $4.7 \%$ higher than the corresponding parameter measured for the cutter ground using the WET method. What is of note in this 
context is the fact that the microhardness of the workpiece surface layer machined with the application of a coolant provided using the MQL-CCA and WET methods was not considerably decreased as compared to the material microhardness before grinding (Fig. 11). In view of the above, there were fewer plastic deformations in the chip creation zone as compared to deformations occurring in application of the MQL or CCA methods. In such conditions, the active abrasive grains, when moving through the material, create material pick-up's of a lower height while the majority of the removed material is transformed into chips as a result of microcutting. This causes the obtaining lower of values of the $R z$ surface roughness parameter as compared with parameter $R z$ measured for a surface ground with the application of the minimum quantity of the coolant (MQL) or cooled during machining with a CCA stream. The reason for obtaining lower $R z$ parameter values is also minimizing the grinding wheel gumming up phenomenon by removing the chips and grinding products left after exiting the grinding zone from its active surface.

In the case of the $S z$ parameter (Fig. 12b), which is due to the lack of sensitivity to the influence of individual accidental elevations and valleys has considerable generalizing properties, while its lowest value, just as in the case of the $R z$ parameter, was for the cutter ground using the WET method of coolant provision during grinding. The $S z$ value for the cutter ground using the MQL-CCA method was $15 \%$ greater in relation to WET, $67 \%$ for the MQL method, and $71 \%$ for the CCA method.

Comparing values of the $R z$ and $S z$ parameters, it is worth noting that the $S z$ parameter value, for each of the four surfaces ground using various methods of coolant provision, are 2.5 to 4 times greater than the $R z$ parameter value. The cause of this may be the varying ways of estimating values of specific parameters. In the case of the $R z$ parameter, it is determined as the sum of the height of the greatest profile height and depth of the lowest depth of the profile inside the elementary section, while the $S z$ parameter is the mean value of the absolute heights of the five highest elevations and five lowest depths within the sampling area. Another reason for the occurrence of the differences in the $R z$ and $S z$ parameter values are the different points of reference against which the specific parameters are calculated. For the profile this is the mean line, while it is the surface for the $3 \mathrm{D}$ measurements. Additionally, surface topography parameters are also influenced by problems related with, for example, maintaining a precise point of reference between the passes and maintaining precise sampling distances on each path in relation to the others.

The negative values of the skewness coefficient Ssk (Fig. 12c) are indicative of obtaining a surface with plainshaped elevations. At the same time, similar Ssk values indicate that the examined surfaces are devoid of accidental extreme deviations such as untypical locations of valleys and elevations.

Comparing the obtained $S k$ parameter values (Fig. 12d), which reflects the core roughness and can constitute the measurement of effective roughness depth after the lapping period, showed that $S k$ for surfaces of cutters ground using the WET, MQL-CCA, and MQL methods are similar and range from 0.488 to $0.512 \mu \mathrm{m}$. In the case of the cutter surface, for which the CCA method was used during grinding, the greatest core height was obtained, namely $0.773 \mu \mathrm{m}$.

The lowest values of the $S p k$ parameter (reduced summit height-Fig. 12e) were measured for cutters undergoing WET, MQL-CCA, and MQL, which is indicative of the high resistance of the examined face surface against abrasion. It needs to be remembered that the lower the value of this parameter, the better the resistance of the surface geometric structure (ST) to abrasion, which is significant in the case of hob cutters for which abrasion is the most common type of mechanical wear of the blades.

\subsection{SEM images of the cutting edges}

Figure 13 presents SEM images of fragments of cutters' cutting edges after grinding using four coolant provision methods-WET, MQL-CCA, MQL, and CCA.

As shown by the SEM images (Fig. 13), on the cutting edges of hob cutters ground with the application of the WET method (WET) and MQL-CCA method, there are no typical grinding defects in the form of chippings or burrs. In the two remaining cases-MQL and CCA, burrs were observed on the cutters' cutting edges, as illustrated in the considerably magnified SEM image (Fig. 14).

The appearance of burrs on the cutting edges of burrs ground using the MQL and CCA methods is most likely caused by occurrence of too high a temperature during the grinding process [1]. Temperature increase in the surface layer causes structural changes and decreasing of the hardness by as much as approximately $90 \mathrm{HV}$ (Fig. 11), thus resulting in increasing the material plasticity. This contributes to scuffing of the material on the ground surface, which results in an increase in roughness (Fig. 12) and the creation of burrs on the cutters' edges.

It should be remembered that the presence of burrs on the cutters' cutting edges has a negative influence on the blade's cutting properties and, just as in the case of the abovediscussed microhardness, roughness, and nicking, it makes the hob cutter's abrasive wear faster during its operation, thus shortening its life. 
Fig. 13 SEM microscopic images $(\times 150)$ of cutting edge fragments after sharpening with different methods of coolant provision: a WET; b MQL-CCA; $\mathbf{c}$ MQL; d CCA
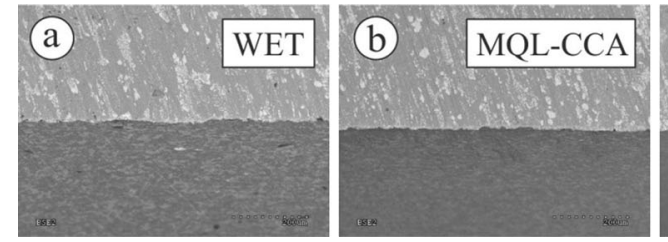

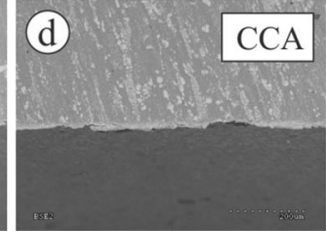

\section{Results of tests on the hob cutters' wear after grinding}

\subsection{Number of cutter teeth affected by measurable wear signs}

Figure 15 presents the distribution of $\mathrm{VB}_{C}$ wear on all of the cutter's teeth, affected by measurable wear signs. The results were obtained for cutters previously ground using four coolant provision methods while grinding the face surface, namely: WET (Fig. 15a), MQL-CCA (Fig. 15b), MQL (Fig. 15c), and CCA (Fig. 15d).

On basis of the graphs presented in Fig. 15, it may be concluded that in all four cases, the hob cutter's teeth are worn unevenly, which is in line with the data in the literature [8, 32]. This unevenness is caused by variability of strains on specific teeth along the blade's edge during hobbing. From the general number of cutting teeth, only some transfer the strains related to cutting while only 2-4 teeth are worn most. Among them, one tooth stands out in terms of the wear level, namely the central tooth whose apex center lies in the plane axis of the machined wheel, parallel to the cutter axis projection onto the head plane of the toothed-wheel rim.

The graphs in Fig. 15 show that while in the initial period of the tool's operation, the number of teeth affected by measurable signs of the cutting edge abrasion signs is minor, as the machining time passes their number increases. It should be noted, however, that the number of discussed cutter teeth changes depending on the applied coolant provision method. The results of observations after $312 \mathrm{~min}$ of hobbing are included in Table 3.

As indicated by the data included in Table 3, the smallest number of teeth for which it was possible to determine the
$\mathrm{VB}_{C}$ parameter value after 312 min of hobbing, was observed for the cutter ground with coolant delivered using the WET method. At the same time, the corresponding number of teeth for the cutter ground employing coolant provision with the MQL-CCA method is only one tooth greater. In the case of the cutter ground with the application of coolant provision using the MQL method and the cutter ground using CCA, wear signs were observed on a greater number of teeth as compared to the cutter for which the conventional coolant provision method was used (WET). The differences are $36 \%$ for using the MQL method and 54\% in the case of the application the CCA method.

The reasons for the determined differences in the wear of cutters ground using comparable methods of cooling the grinding zone lies in the different material microhardness obtained, depending on the method of coolant provision during grinding. Since in the case of the application of the MQLCCA method the microhardness changes in relation to the material before grinding are similar to the changes obtained for the WET method, the number of teeth affected by visible wear signs are almost the same for both methods. In the case of cutters ground with non-simultaneous application of the MQL and CCA methods, the decrease in microhardness is considerably greater, which translates into a greater number of cutter's teeth on which signs of wear are visible.

\subsection{Course of wear of the most loaded cutter tooth}

Figure 16 presents the course of $\mathrm{VB}_{C}$ wear curves for the most worn blade of specific hob cutters and includes values of the $\mathrm{VB}_{C}$ coefficient measured after $312 \mathrm{~min}$ of machining.

On basis of the $\mathrm{VB}_{C}$ parameter value changes presented in Fig. 16, it may be observed that for the hob cutter
Fig. 14 SEM microscopic images $(\times 500)$ of cutting edge fragments with burrs formed after sharpening with different methods of coolant provision: a MQL; b CCA
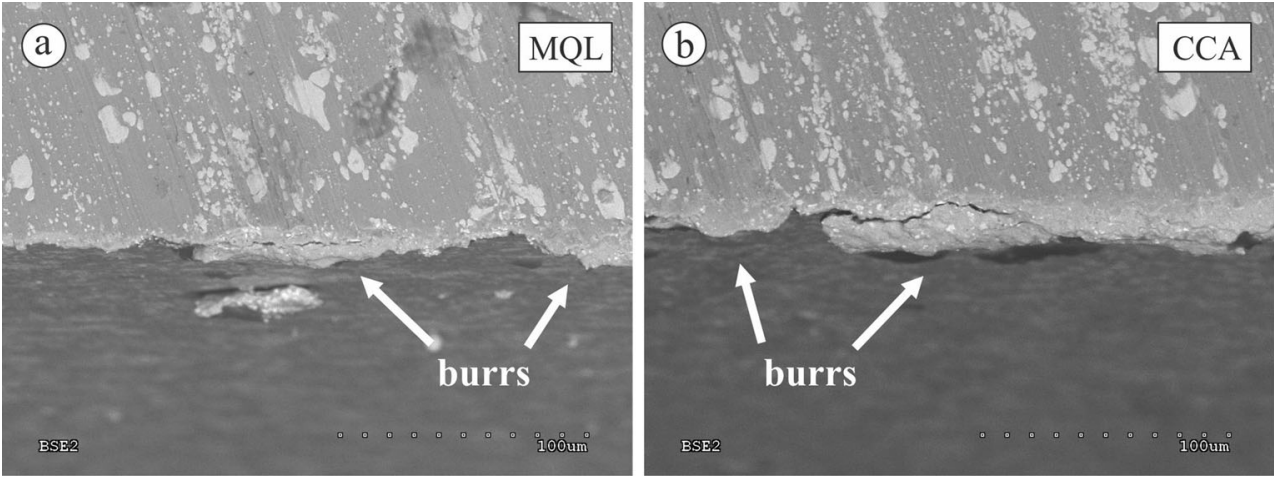

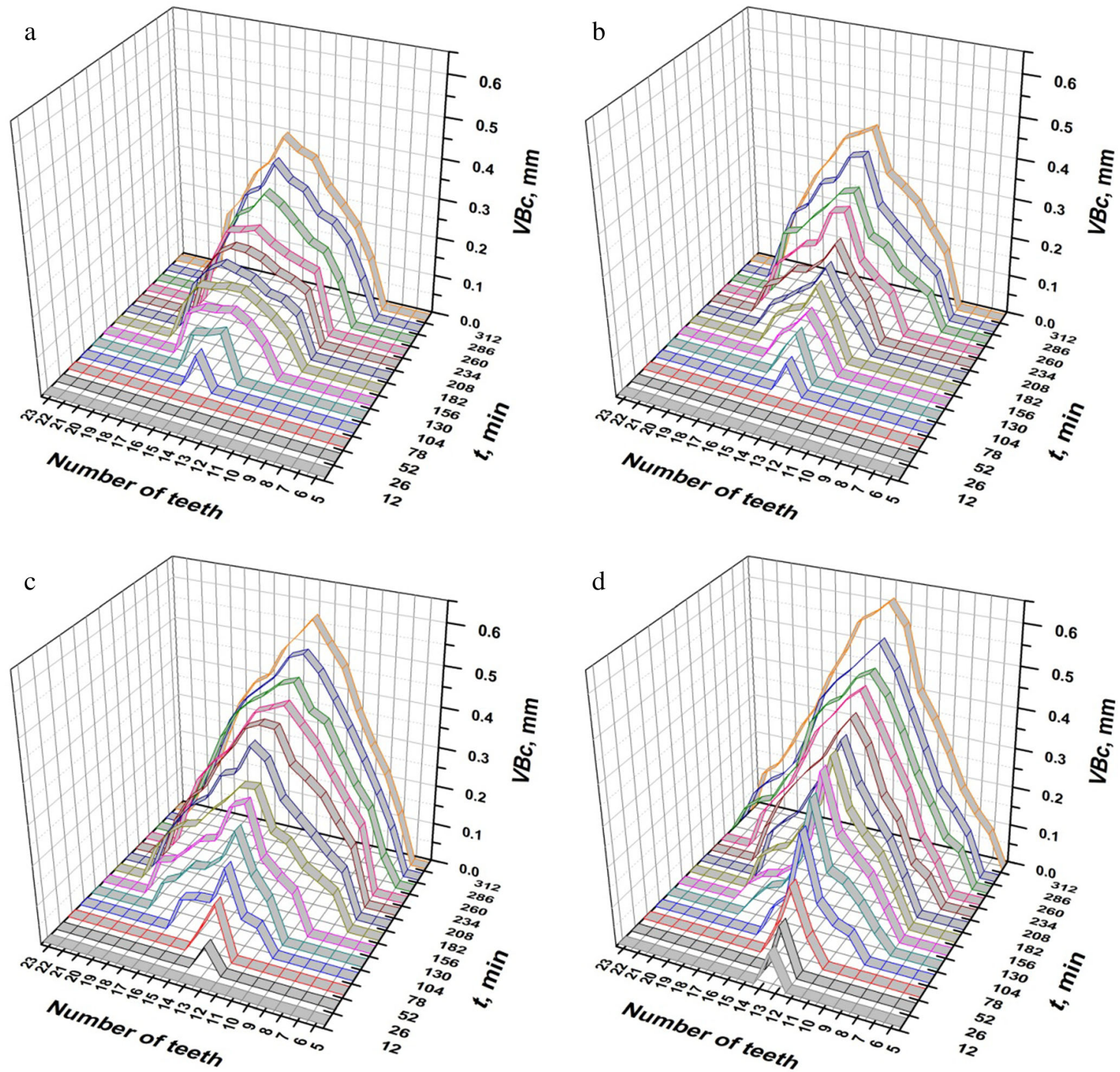

Fig. 15 Distribution of $\mathrm{VB}_{C}$ wear on subsequent cutter teeth while sharpening cutters using different coolant provision methods: a WET, b MQL-CCA, c MQL, d CCA

ground using the MQL-CCA method, no considerable shortening of life occurred as compared to the cutter ground using the WET method. On the 312th machining

Table 3 Number of teeth with visible signs of wear after 312 min of milling

\begin{tabular}{lllll}
\hline $\begin{array}{l}\text { The method of coolant } \\
\text { delivery during sharpening }\end{array}$ & WET & MQL-CCA & MQL & CCA \\
\hline $\begin{array}{l}\text { Number of teeth with } \\
\text { visible signs of wear }\end{array}$ & 11 & 12 & 15 & 17 \\
\hline
\end{tabular}

minute, the $\mathrm{VB}_{C}$ wear index for the cutter being ground using cooling and lubrication with the MQL-CCA method was only $6 \%$ higher than the $\mathrm{VB}_{C}$ index for the cutter being ground using the WET cooling method. The wear curves for these two cutters show similar courses, which is indicative of a lack of influence of the surface layer condition resulting from the method of coolant provision during grinding onto the intensity of the tool wear process during tangential grinding. The above conclusion is also confirmed by the fact that for both cutters, the visible wear mark on the face surface appears in the same hobbing period, i.e., between the 52nd and 78th minute. 
Fig. 16 The $\mathrm{VB}_{C}$ wear cycle of the most worn blade of hob cutters sharpened with the use of different cooling delivery methods: a WET; b MQL-CCA; c MQL; d CCA

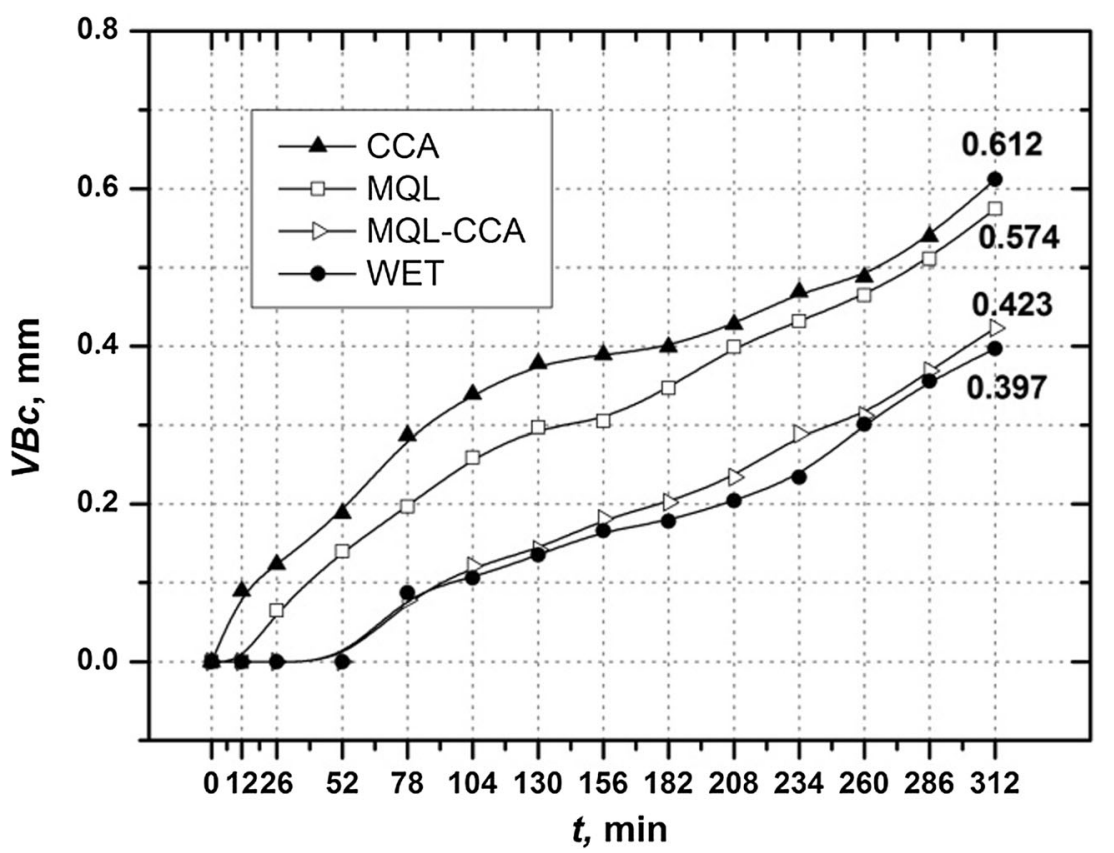

In the case of the cutter for which during grinding the coolant was provided with the MQL method and the cutter cooled with the CCA stream, the influence of the increase of roughness obtained during grinding onto the moment of appearance of measurable wear signs on the cutter blades may be clearly observed. In the case of the hob cutter ground using the MQL method, wear appears between the 13th and 26th hobbing minute, while for the CCA cutter, this had already occurred before the 13th minute of hobbing. This confirms the previous statement that the greater the cutting edge nicking, the more intensive the tool wear as a result of the abrasion of the nicks on the initial stage of cutting. The influence of the face surface condition obtained after grinding is also revealed in the wear curves and their intensity up to the 312 th minute of machining. Regarding cutters for which during grinding the MQL and CCA methods were used separately, although the wear curve inclination is similar to the two previously described curves, the end $\mathrm{VB}_{C}$ value for the cutter ground with application of the MQL method is $45 \%$ higher than in the case of the cutter ground with application of an emulsion (WET), while in the case of the cutter ground using the CCA stream, the end $\mathrm{VB}_{C}$ value is $54 \%$ higher than in the case of the conventionally ground cutter (WET).

\section{Conclusions}

On basis of the results obtained in relation to the applied test conditions, the following conclusions were drawn:

1. The course of wear and $\mathrm{VB}_{C}$ parameter values obtained for the four cutters ground with different coolant provision methods indicate that the MQL-CCA method can be an alternative to the application of the conventional WET method. This is confirmed by both the nature of wear of the most loaded cutter tooth, as well as the number of cutter teeth affected by measurable signs of cutting edge abrasion.

2. Grinding hob cutters with the application of the MQLCCA method does not cause significant changes in the surface layer microhardness as compared to the WET method, which translates into similar courses for both wear curves.

3. The microhardness results obtained for the MQL and CCA methods, used separately, show a considerable unacceptable decrease in the tool face surface microhardness. This is indicative of the tempering of a thin surface layer and explains the faster abrasive wear of these cutters as compared with cutters in which the coolant was delivered with the WET method and the MQL-CCA method.

4. The face surface roughness, obtained during grinding with the application of the MQL-CCA method, is comparable to the values obtained for the WET method. This is indicative of providing comparable grinding conditions. The fact of obtaining approximate roughness results also means that the methods allow one to obtain proper quality of the cutters' cutting blades, which has influence on their later wear during hobbing. This is confirmed by SEM images of the cutting edges.

The research results display the great potential of the MQLCCA method, both in terms of its industrial application and conducting further scientific research. The MQL-CCA method can be used to supply a coolant and lubricant when grinding the 
rake face of hob cutters under industrial conditions. This applies both to sharpening with conventional sharpeners and to numerically controlled sharpening centers. This conclusion was based on an analysis of the technical, environmental, and economic aspects related to the flood method. From a technical point of view, the test results indicate that the application of the MQL-CCA method does not impair the performance of the hob cutters. From an environmental point of view, the use of MQLCCA reduces risks to the environment, as well as the health and safety of workers, mainly by reducing coolant expenditure and using neutral coolants. From an economic point of view, the choice of this method involves a small and one-off cost of purchasing equipment delivering the coolant and lubricant in the grinding zone and the need to purchase only lubricant for use in the MQL method.

Further research should focus on improving the lubricating and cooling performance of the MQL-CCA method, for example, by using grinding wheels with macro-discontinuity on the active surface. At the same time, the results of the research indicate that it is justified to conduct research on the use of the MQL-CCA method in grinding various types of cutting tools or to use it in other varieties of the grinding process.

Funding This study did not receive any grant funding.

\section{Compliance with ethical standards}

Conflict of interest The authors declare that they have no competing interests.

Open Access This article is distributed under the terms of the Creative Commons Attribution 4.0 International License (http:// creativecommons.org/licenses/by/4.0/), which permits unrestricted use, distribution, and reproduction in any medium, provided you give appropriate credit to the original author(s) and the source, provide a link to the Creative Commons license, and indicate if changes were made.

Publisher's Note Springer Nature remains neutral with regard to jurisdictional claims in published maps and institutional affiliations.

\section{References}

1. Aurich JC, Dornfeld D, Arrazola PJ, Franke V, Leitz L, Min S (2009) Burrs - analysis, control and removal. CIRP annalsmanufacturing technology 58:519-542

2. Barczak LM, Batako ADL, Morgan MN (2010) A study of plane surface grinding under minimum quantity lubrication (MQL) conditions. Int J Mach Tool Manu 50:977-985

3. Benedicto E, Carou D, Rubio EM (2017) Technical, economic and environmental review of the lubrication/cooling systems used in machining processes. Procedia Eng 184:99-116

4. Bianco G (2004) Gear hobbing. Novaprint, Bologna

5. Bianchi EC, Aguiar PR, Diniz AE, Canarim RC (2011) Optimization of ceramics grinding. In: Advances in ceramics-synthesis and characterization, processing and specific application. InTech
6. Bianchi EC, Rodriguez RL, Hildebrandt RA, Lopes JC, Mello HJ, Silva RB, Aguiar PR (2018) Plunge cylindrical grinding with the minimum quantity lubrication coolant technique assisted with wheel cleaning system. Int J Adv Manuf Technol 95:2907-2916

7. Bianchi EC, Sato BK, Sales AR, Lopes JC, Mello HJ, Sanchez LEA, Diniz AE, Aguiar PR (2018) Evaluating the effect of the compressed air wheel cleaning in grinding the AISI 4340 steel with CBN and MQL with water. Int J Adv Manuf Technol 95:28552864

8. Bouzakis KD, Lili E, Michailidis N, Friderikos O (2008) Manufacturing of cylindrical gears by generating cutting processes: a critical synthesis of analysis methods. CIRP annals - manufacturing technology 57:676-696

9. Debnath S, Reddy MM, Yi QS (2014) Environmental friendly cutting fluids and cooling techniques in machining: a review. J Clean Prod 83:33-47

10. Fratila D (2010) Macro-level environmental comparison of neardry machining and flood machining. J Clean Prod 18:1031-1039

11. Hall H (2006) Tool and cutter sharpening. Special Interest Model Books Ltd, Hemel Hempstead

12. Garcia E, Pombo I, Sanchez JA, Ortega N, Izquierdo B, Plaza S, Marquinez JI, Heinzel C, Mourek D (2013) Reduction of oil and gas consumption in grinding technology using high pour-point lubricants. J Clean Prod 51:99-108

13. Gawroński Z, Sawicki J (2006) Technological surface layer selection for small module pitches of gear wheels working under cyclic contact loads. Mater Sci Forum 513:69-74

14. Jalali Azizpour M, Mohammadi Majd H (2010) Wear mechanisms in high speed steel gear cutting tools. World Acad Sci Eng Technol 4:739-741

15. Kruszyński BW, Wójcik R (2001) Residual stress in grinding. J Mater Process Technol 109:254-257

16. Lee P-H, Lee SW (2011) Experimental characterization of microgrinding process using compressed chilly air. Int J Mach Tools Manuf 51:201-209

17. Madanchi N, Kurle D, Winter M, Thiede S, Herrmann C (2015) Energy efficient process chain: the impact of cutting fluid strategies. Procedia CIRP 29:360-365

18. Malkin S, Guo C (2008) Grinding technology: theory and applications of machining with abrasives, 2nd edn. Industrial Press Inc., New York

19. Moderow R (1992) The right and wrong of modern hob sharpening. Gear technology Jan/Feb:34-38

20. Nguyen T, Zhang LC (2003) An assessment of the applicability of cold air and oil mist in surface grinding. J Mater Process Technol 140:224-230

21. Oliveira DJ, Guermandi LG, Bianchi EC, Diniz AE, Aguiar PR, Canarim RC (2012) Improving minimum quantity lubrication in CBN grinding using compressed air wheel cleaning. J Mater Process Technol 212:2559-2568

22. Pereira $\mathrm{O}$, Català $\mathrm{P}$, Rodriguez $\mathrm{A}$, Ostra $\mathrm{T}$, Vivancos J, Rivero A, López-de-Lacalle LN (2015) The use of hybrid $\mathrm{CO}_{2}+\mathrm{MQL}$ in machining operations. Procedia Eng 132:492-499

23. Pusavec F, Krajnik P, Kopac J (2010) Transitioning to sustainable production - part I: application on machining technologies. J Clean Prod 18:174-184

24. Rech J (2006) Influence of cutting edge preparation on the wear resistance in high speed gear hobbing. Wear 261:505-512

25. Ruzzi RS, Belentani RM, Mello HJ, Canarim RC, D'Addona DM, Diniz AE, Aguiar PR, Bianchi EC (2017) MQL with water in cylindrical plunge grinding of hardened steels using CBN wheels, with and without wheel cleaning by compressed air. Int J Adv Manuf Technol 90:329-338

26. Saberi A, Rahimi AR, Parsa H, Ashrafijou M, Rabiei F (2016) Improvement of surface grinding process performance of CK45 soft 
steel by minimum quantity lubrication (MQL) technique using compressed cold air jet from vortex tube. J Clean Prod 131:728-738

27. Sanchez JA, Pombo I, Alberdi R, Izquierdo B, Ortega N, Plaza S, Martinez-Toledano J (2010) Machining evaluation of hybrid MQL$\mathrm{CO}_{2}$ grinding technology. J Clean Prod 18:1840-1849

28. Sawicki J, Kruszyński B, Wójcik R (2017) The influence of grinding conditions on the distribution of residual stress in the surface layer of 17CrNi6-6 steel after carburizing. Adv Sci Technol-Res J 11(2):17-22

29. Senevirathne SWMAI, Fernando MARV (2012) Effect of cryogenic cooling on machining performance on hard to cut metals - a literature review. Proc. National Eng Conf, 27 February, Sri Lanka, 38-46

30. Sharma VS, Singh G, Sørby K (2015) A review on minimum quantity lubrication for machining processes. Mater Manuf Process 30(8):935-953

31. Silva LR, Corrêa ECS, Brandão JR, de Ávila RF (2013) Environmentally friendly manufacturing: behavior analysis of minimum quantity of lubricant-MQL in grinding process. J Clean Prod. https://doi.org/10.1016/j.jclepro.2013.01.033
32. Stachurski W (2012) Application of minimal quantity lubrication in gear hobbing. Mech Mech Eng 16(2):133-140

33. Stachurski W, Wójcik R (2015) Method for introducing cooling agent to the grinding area during sharpening of blades of the hobbing cutter. Polish patent No. PAT.222435

34. Stachurski W (2015) Influence of axial feed in hobbing with minimal quantity lubrication (MQL) on wear of the hob and cutting forces. Sci J Silesian Univ Technol Series Transp 89:155-161

35. Stachurski W, Midera S, Kruszyński B (2016) Mathematical model describing the course of the process of wear of a hob cutter for various methods of cutting fluid supply. Eksploat Niezawodn Maintenance and Reliability 18(1):123-127

36. Stachurski W, Sawicki J, Wójcik R, Nadolny K (2018) Influence of application of hybrid MQL-CCA method of applying coolant during hob cutter sharpening on cutting blade surface condition. J Clean Prod 171:892-910

37. Tawakoli T, Hadad MJ, Sadeghi MH (2010) Influence of oil mist parameters on minimum quantity lubrication-MQL grinding process. Int J Mach Tool Manu 50:521-531 